\title{
Increased task demand during spatial memory testing recruits the anterior cingulate cortex
}

\author{
Joshua K. Carr, Neil M. Fournier, and Hugo Lehmann \\ Department of Psychology, Trent University, Peterborough, Ontario K9J 7B8, Canada
}

\begin{abstract}
We examined whether increasing retrieval difficulty in a spatial memory task would promote the recruitment of the anterior cingulate cortex (ACC) similar to what is typically observed during remote memory retrieval. Rats were trained on the hidden platform version of the Morris Water Task and tested three or $30 \mathrm{~d}$ later. Retrieval difficulty was manipulated by removing several prominent extra-pool cues from the testing room. Immediate early gene expression (c-Fos) in the ACC was greater following the cue removal and comparable to remote memory retrieval (30-d retention interval) levels, supporting the view of increased ACC contribution during high cognitive-demand memory processes.
\end{abstract}

[Supplemental material is available for this article.]

Long-term systems consolidation suggests that memories that are initially dependent on the hippocampus (HPC) become increasingly represented in other cortical structures over time, such that they can eventually survive complete HPC damage (Squire and Alvarez 1995; Frankland and Bontempi 2005). The anterior cingulate cortex (ACC) is one structure that is thought to come to support these HPC-independent memories. This is based largely on findings suggesting that inactivation or damage to the ACC impairs the recall of remote memories while sparing recent ones (Frankland et al. 2006; Teixeira et al. 2006; Ding et al. 2008) and that the ACC shows greater activation during recall of a remote memory than a recent one. For example, Teixeira et al. (2006) found that the retrieval of a remote ( 1 mo old) spatial memory in mice elicited greater expression of the immediate-early genes c-Fos and zif268 in the ACC than retrieval of a recent $(1 \mathrm{~d}$ old) memory, concluding that spatial memory becomes consolidated and dependent on the ACC over a protracted period of time.

Although these previous findings suggest that the ACC contributes to the recall of remote memories, these observations could be alternatively explained by the increased cognitive demand that would follow the retrieval of older and temporally degraded memories (Rudy et al. 2005). Specifically, Rudy et al. (2005) proposed that memories, through either forgetting or interference, become weaker with the passage of time, which in turn requires greater cognitive effort for successful retrieval. This increase in cognitive demand would also cause the recruitment of additional cortical structures, including the ACC, in order to overcome the retrieval difficulty. According to this view, the ACC would not be directly involved in long-term systems consolidation and the storage of remote memories per se, but would play a key role in additional cognitive processes associated with the retrieval of remote memories. The aim of this study was to assess whether the ACC is indeed recruited under retrieval conditions that require greater cognitive processing.

If the role of the ACC in remote memory is due to an increase in cognitive processing to compensate for the retrieval difficulty of a degraded memory, then it should be possible to increase ACC activation for a recent memory by making the memory more difficult to retrieve. The current experiment involved a re-

\section{Corresponding author: hugolehmann@trentu.ca}

Article is online at http://www.learnmem.org/cgi/doi/10.1101/lm.042366. 116. trieval difficulty manipulation in the hidden platform version of the Morris water task (MWT) - a spatial memory task often used with rats and mice. This task involves the animal learning and remembering the location of a static submerged (i.e., hidden) platform within a pool in order to escape from the water. A cognitive map of the platform location is established by making use of extra-pool cues present in the testing room (Morris 1984; Sutherland and Hamilton 2004). Importantly, past work has shown that ACC activation is greater following the retrieval of a remote than a recent memory in this task (Teixeira et al. 2006; Lopez et al. 2012; Wartman and Holahan 2013). However, because performance on the MWT is sensitive to cue-availability (Lopez et al. 2012), it is therefore possible to increase retrieval difficulty during the retention test by removing some of the cues from the room.

We trained three groups of adult ( 3 mo old) male Long-Evans rats (Charles River, St. Constant, Quebec) on the hidden platform version of the MWT in a room rich with extra-pool cues (e.g., bookshelf, posters on wall, door to the room, and an artificial tree; see Supplemental Fig. S1A). One group received a retention test $3 \mathrm{~d}$ following the end of acquisition (Recent condition; $n=$ 8), another group $30 \mathrm{~d}$ after acquisition (Remote condition; $n=$ 8 ), and a third group $3 \mathrm{~d}$ after acquisition, but prominent spatial cues were removed from the testing room at the time of the retention test (Altered condition; $n=8$; see Supplemental Fig. S1B) to make retrieval more difficult. Acquisition training for each rat involved two training sessions over two consecutive days. Each training session consisted of 12 swim trials, with the tenth being a probe trial and all others standard escape trials. An escape trial involved the rats being placed in the water facing the wall of the pool in the center of one of the nonplatform pool quadrants. The maximum duration of an escape trial was $60 \mathrm{sec}$ or until the rats climbed onto the platform. Once on the platform, the rats were removed from the pool after $5 \mathrm{sec}$. If a rat did not find the platform within the $60 \mathrm{sec}$, they were removed from the pool until the next trial. The start location for each trial was varied

\footnotetext{
(C) 2016 Carr et al. This article is distributed exclusively by Cold Spring Harbor Laboratory Press for the first 12 months after the full-issue publication date (see http://learnmem.cshlp.org/site/misc/terms.xhtml). After 12 months, it is available under a Creative Commons License (Attribution-NonCommercial 4.0 International), as described at http://creativecommons.org/licenses/by$\mathrm{nc} / 4.0 /$.
} 
pseudorandomly across the three nonplatform quadrants. For the two probe trials, the procedure was the same as for the escape trials with the exception that the platform was removed from the pool and that the duration of the trial was limited to $30 \mathrm{sec}$. The rats were given a minimum rest period of $1 \mathrm{~min}$ between each trial. The retention test consisted of a single 30 -sec probe trial, which followed the same protocol as the acquisition probe trials. A retention probe trial was deemed a better test because it provides additional data relative to a standard escape trial (e.g., percent time in target/platform quadrant) and involves extinction rather than reacquisition.

Sixty minutes following their retention test, the rats were sacrificed and their brains removed and fixed for tissue processing. Following fixation, the brains were sectioned and labeled for c-Fos protein, a marker of neural activity (Tischmeyer and Grimm 1999). Noteworthy, evidence suggests that a 60 -min testing-tosacrifice interval is sufficient for detecting behaviorally induced changes in c-Fos protein (Tischmeyer and Grimm 1999; Zangenehpour and Chaudhuri 2002; Kubik et al. 2007). Expression of c-Fos protein was then quantified in the ACC microscopically according to unbiased/assumption-free stereology practices using the disector principle (Sterio 1984; Mouton 2002). Expression of c-Fos was also assessed in the CA1 field of the HPC because this region is known to support spatial memory (Morris 1984; Suther- land and Hamilton 2004) and because memories are postulated to consolidate from the HPC to the ACC over time (Frankland and Bontempi 2005). All histological and stereological procedures are described in detail in the Supplemental Material.

The average swim distance for each group across escape trials during acquisition is illustrated in Figure 1. A one-way ANOVA revealed a significant main effect of Escape Trial $\left(F_{(23,21)}=25.183\right.$, $P<0.001)$, indicating that the rats swam shorter distances across trials and suggesting that they learned the platform location. No significant main effect of Group $\left(F_{(2,21)}=0.184, P=0.83\right)$ or interaction $\left(F_{(46,21)}=0.858, P=0.73\right)$ was found, suggesting that all three groups showed a similar learning pattern. The acquisition probe trials corroborate this inference. Specifically, one-sample $t$-tests revealed that all groups spent significantly more time $(P s<0.05)$ in the target quadrant than expected by chance (25\%), and a one-way ANOVA did not reveal significant group differences on either day of testing (Day $1 F_{(2,21)}=1.62, P=0.221$, Day $\left.2 F_{(2,21)}=1.10, P=0.35\right)$.

The results of the retention test probe trial are illustrated in Figure 2. The distance traveled to the first crossing of the former target location did not significantly differ across groups $\left(F_{(2,17)}=\right.$ $1.82, P=0.19)$. This distance was also comparable to that of their final acquisition trials, suggesting that all groups remembered the location of the escape platform. When considering percent time

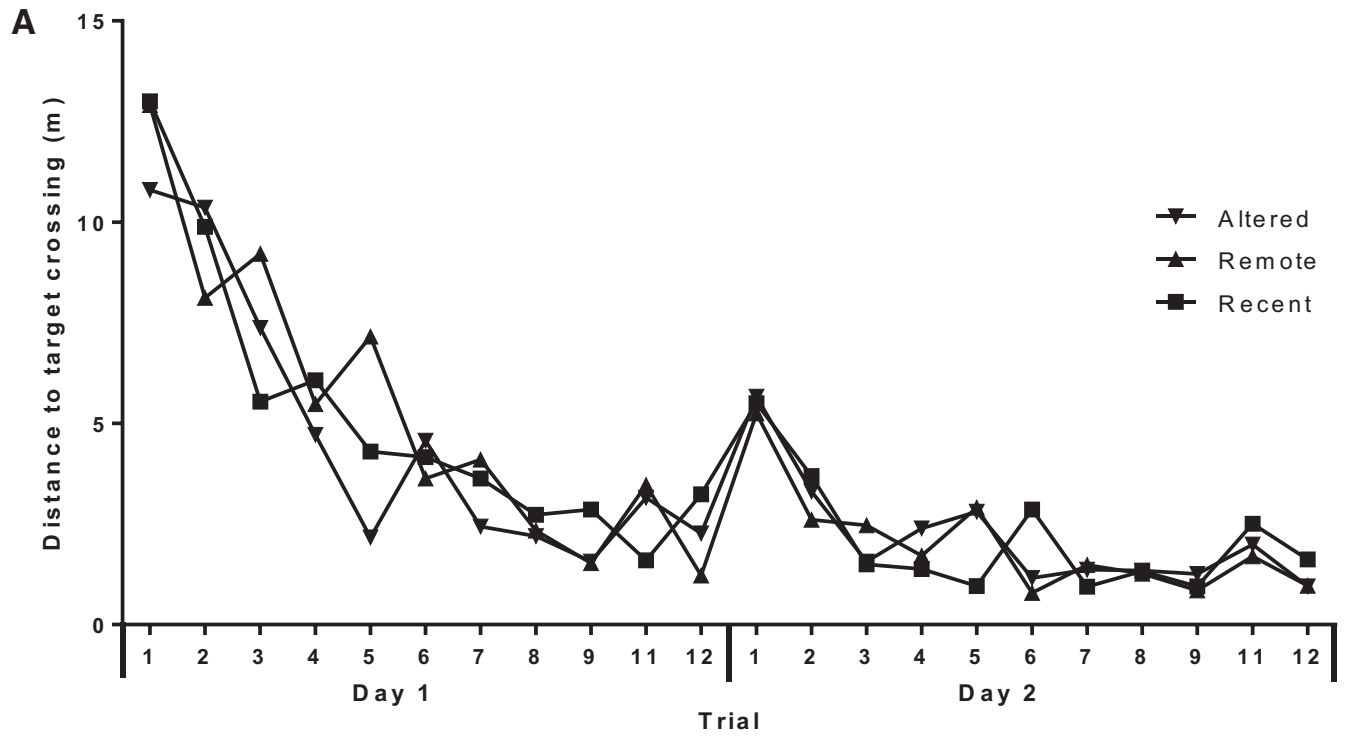

B

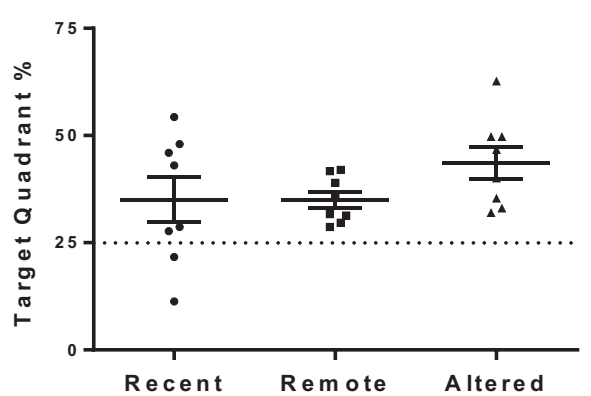

C

Day 2 Probe

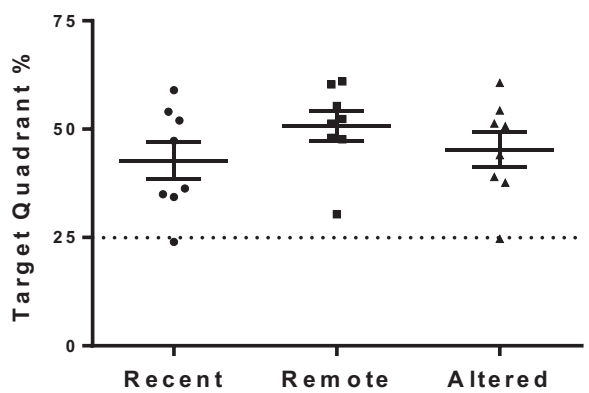

Figure 1. (A) Acquisition curves illustrating the decrease in distance travelled to the platform over trials during the two training days $(P<0.001)$, which did not significantly differ across groups $(P=0.73)$. Percent time the rats spent in the target quadrant during the probe trial on Day $1(B)$ and Day $2(C)$ of acquisition (individual data points with group mean \pm SEM). All groups spent a significantly greater proportion of time in the target quadrant $(P S<0.05)$ than predicted by chance (25\%; dotted line). 
A

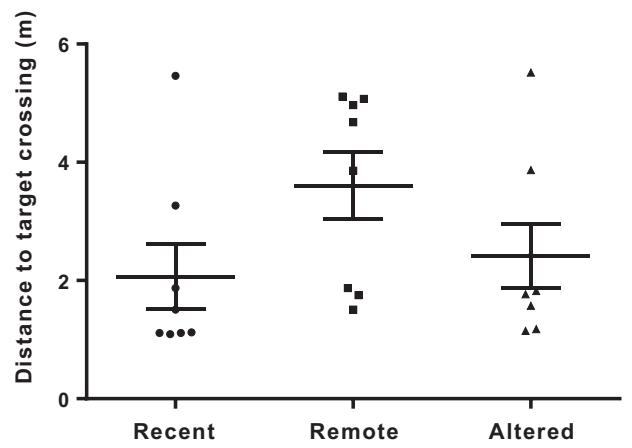

B

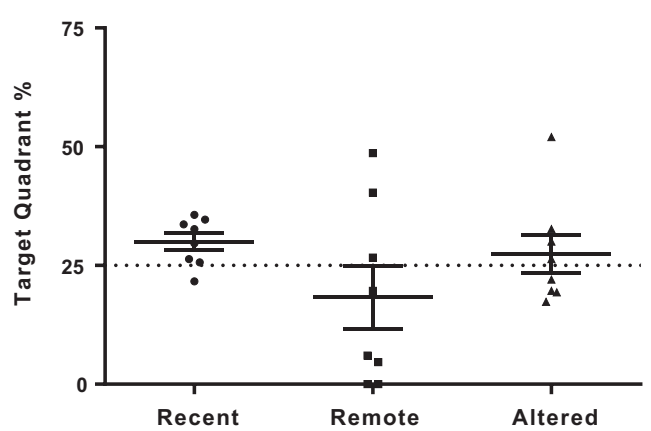

Figure 2. Graphs are plotted as individual data points with their respective group mean \pm SEM. (A) Distance travelled to cross the former hiddenplatform/target location during the retention test (probe trial) for each group. Swim distances did not differ across groups $(P=0.19)$ and were comparable to those observed on the final trials of acquisition training, suggesting that the platform location was remembered. $(B)$ Percent time spent swimming in the target quadrant for each group. The dotted line represents chance values (25\%). Only the Recent group showed a preference for the target quadrant that was significantly above chance (Recent $P<0.025$; Remote $P=0.345$; Altered $P=0.564$ ), suggesting that retention was not as strong in the Remote and Altered groups.

in the former target quadrant, a more sensitive measure of retention performance, the Remote and Altered groups did not demonstrate memory as strong as the Recent group. Specifically, only the Recent group showed a preference for the target quadrant that was significantly greater than chance (Recent $t_{(7)}=2.82, P<0.025$; Remote $t_{(7)}=-1.01, P=0.345$; Altered $\left.t_{(7)}=0.60, P=0.564\right)$. Thus, the Recent group persevered in searching for the platform in its former location, whereas the Remote and Altered groups did not. This suggests that the spatial memory degraded (i.e., forgetting) for the Remote group and that the removal of spatial cues affected retention performance for the Altered group, mainly by increasing group variability. Accordingly, we infer that the cognitive demand during the retention test for these two groups was more than that for the Recent group.

Retention-induced c-Fos expression in the ACC and CA1 are reported for each group in Figure 3. A Homecage control group (no behavioral testing; $n=5$ ) was also included to confirm that the experimental manipulations affected c-Fos expression. A oneway ANOVA on the ACC data revealed a significant group difference $\left(F_{(3,25)}=8.143, P<0.001\right)$. Pairwise comparisons revealed that all three groups tested for retention in the MWT showed significantly more c-Fos-positive cells than the Homecage control group $(P<0.01)$. Additionally, the analyses revealed that the Remote and Altered groups showed significantly more ACC c-Fos-positive cells than the Recent group $(P<0.001)$ and did not differ significantly from one another $(P=0.628)$. A one-way ANOVA on the CA1 data was not statistically significant $\left(F_{(3,25)}=2.078 P=0.132\right)$. Nevertheless, pairwise comparisons revealed, as expected, that the combined three groups tested in the pool showed significantly greater CA1 c-Fos positive cells than the Homecage control group $(P<0.05)$, and that the three groups did not significantly differ amongst each other (Ps $>0.05$ ).

In the current study, the reversed temporal gradient in ACC activation when examining immediate early gene expression following recent and remote memory retrieval seemingly supports long-term systems consolidation views. Indeed, unbiased stereological quantification of c-Fos expression in the ACC confirmed a greater number of c-Fos-positive cells following retrieval of the remote over the recent memory, similar to the findings of other studies (Teixeira et al. 2006; Lopez et al. 2012; Wartman and Holahan 2013). The recruitment of the ACC for remote memory is typically interpreted as evidence that the memory becomes dependent on and stored in the ACC (Frankland and Bontempi 2005; Weible 2013). Rudy et al. (2005) argue, however, that the
A

ACC

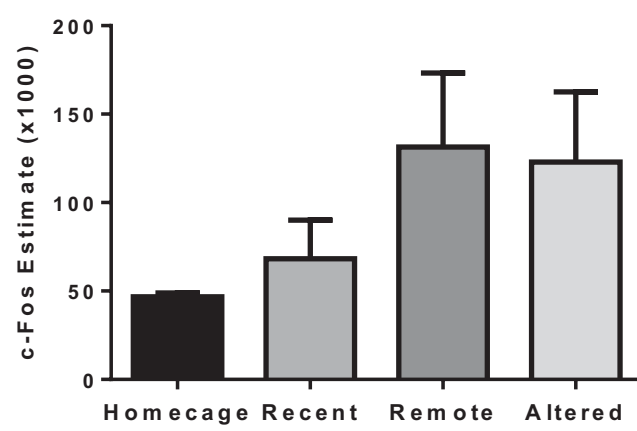

B

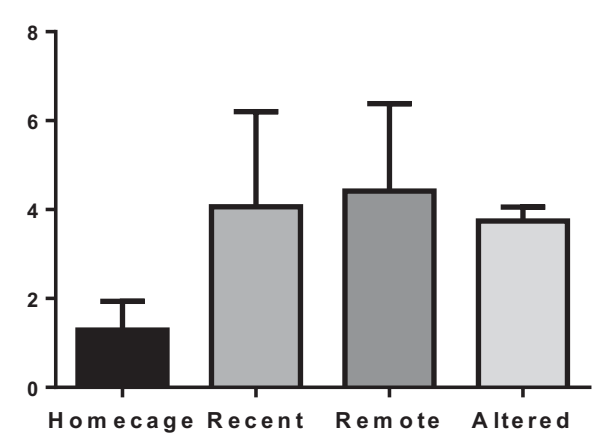

Figure 3. Mean ( \pm SEM) unbiased/assumption free stereological estimates of $\mathrm{c}$-Fos positive cells in the ACC $(A)$ and CA1 (B) for the Recent, Remote, Altered, and Homecage-control groups. In the ACC, all groups showed greater c-Fos expression than the Homecage group (Ps $<0.05)$. More important, the Remote and Altered groups showed significantly greater ACC C-Fos expression than the Recent group $(P<0.001)$ and were not significantly different from one another $(P=0.628)$. In the $C A 1$, the Recent, Remote, and Altered groups overall showed greater c-Fos expression than the Homecage group $(P<0.05)$, but these groups did not significantly differ from one another $\left(P_{S}>0.05\right)$. 
greater ACC activation for remote memory may also be explained by an increase in cognitive demand associated with the retrieval of memories that degrade over time. Thus, the recruitment of the ACC for memory would be significantly impacted by conditions that promote increases in cognitive demand, such as reducing cue-availability during testing. If this is accurate, then increasing cognitive demand for a recent memory should similarly recruit the ACC. This interpretation is consistent with the results from the present study in which removal of prominent spatial cues during the recent memory probe testing resulted in greater ACC recruitment. Our unbiased stereological quantification also revealed more c-Fos-positive cells in the ACC of the Altered group than the Recent group, which both had identical learning-to-test intervals but more importantly differing spatial cue availabilities at the time of testing. Thus, the greater ACC activation in the Altered group cannot be accounted for by systems consolidation. Moreover, the rats tested in the Altered condition had ACC c-Fos positive cell estimates comparable to the rats tested in the Remote condition. These findings provide, to our knowledge, the first empirical evidence supporting the view of Rudy et al. (2005) that the ACC's contribution to retrieving older memories is associated with increased cognitive demand, rather than the ACC acting as a storage site for these memories. The specific cognitive processes (e.g., attention, decision-making, discrimination difficulty, errordetection, etc.) causing the increased activation, however, presently remain undetermined.

It is important to note that the current findings do not necessarily preclude the possibility that the ACC is involved in systems consolidation and comes to store memories that are believed to become HPC-independent. For instance, dendritic spine growth in the ACC for context memories requires weeks to complete (Restivo et al. 2009; Vetere et al. 2011), which is consistent with long-term systems consolidation views. However, a more recent study showed no differences in dendritic spine complexity in the ACC between recent and remote memories (Wartman and Holahan 2014). Regardless of these discrepant findings, the current evidence supports the cognitive processing hypothesis of Rudy et al. and suggests that future studies involving remote memory and the ACC should take into account cognitive demand when interpreting ACC activation during memory retrieval.

For the CA1, c-Fos expression did not differ across our three experimental groups, suggesting that the HPC was equally involved in the performance of the spatial memory task regardless of cue-availability or the passage of time. This finding is inconsistent with the systems consolidation view, which suggests that the involvement of the HPC in supporting a memory should decrease as the memory ages and consolidates into other structures (Squire and Alvarez 1995). This pattern is, however, consistent with previous studies indicating that HPC lesions do not produce a temporal gradient on spatial memory tasks (Sutherland et al. 2001; Clark et al. 2005; Martin et al. 2005) and that the HPC is recruited on these tasks regardless of memory age (Teixeira et al. 2006).

Lopez et al. (2012) also examined the relationship between cue-availability and ACC recruitment in spatial memory. Specifically, they trained rats in the MWT in either a cue-rich or cue-sparse environment and then tested them for retention in their respective environment at a recent $(5 \mathrm{~d})$ or remote $(25 \mathrm{~d})$ time point. Their intention, similar to ours, was to increase cognitive demand and examine ACC activation. They found that the ACC was more active during recall of a remote memory, but only when cue-availability was rich. Hence, they found a timedependent recruitment for the ACC, which they argued supports long-term systems consolidation. Moreover, from their findings they concluded that increased cognitive demand did not promote the recruitment of the ACC, contradicting the cognitive processing hypothesis of Rudy et al. (2005). It is important to note, how- ever, that this study explicitly manipulated cue availability during acquisition/learning rather than during retrieval. Thus, they did not directly assess the main feature of the cognitive processing hypothesis that corresponds to compensatory processes for the loss of retrieval cues associated with memory decay. We believe that the design of the current experiment more accurately examines the cognitive processing hypothesis because the cue-availability manipulation was conducted at the time of retrieval. This manipulation likely mimicked increased cognitive processes associated with natural forgetting and the ACC was recruited soon after learning with reduced/altered cue-availability during retrieval, which supports the cognitive processing hypothesis of Rudy et al. (2005).

The ACC has previously been shown to support a variety of higher-order cognitive functions unrelated to memory storage, including attention (Carter et al. 1998; Bush et al. 2000; Weissman 2004) and decision-making (Devinsky et al. 1995; Kennerley et al. 2006). It is therefore possible that the proposed role of the ACC in storing and retrieving remote memories (Frankland and Bontempi 2005; Weible 2013) may be related to the incidental recruitment of higher-order cognitive functions in order to compensate for the increased difficulty in retrieving a degraded memory. Our findings provide empirical support for this suggestion by demonstrating comparable recruitment of the ACC due to increased retrieval difficulty without sufficient time for systems consolidation to have taken place. Additionally, these results establish the importance of future studies considering the effect of increased cognitive processing when comparing recent and remote memory retention.

\section{Acknowledgments}

We thank the Natural Sciences and Engineering Research Council of Canada (NSERC; 355934; http://www.nserc-crsng.gc.ca) and the Canada Foundation for Innovation (CFI; 29438; http://www .innovation.ca) for funding this research. The funders had no role in study design, data collection and analysis, decision to publish, or preparation of the manuscript.

\section{References}

Bush G, Luu P, Posner MI. 2000. Cognitive and emotional influences in anterior cingulate cortex. Trends Cogn Sci 4: 215-222.

Carter CS, Braver TS, Barch DM, Botvinick MM, Noll D, Cohen JD. 1998. Anterior cingulate cortex, error detection, and the online monitoring of performance. Science 280: 747-749.

Clark RE, Broadbent NJ, Squire LR. 2005. Hippocampus and remote spatial memory in rats. Hippocampus 15: 260-272.

Devinsky O, Morrell MJ, Vogt BA. 1995. Contributions of anterior cingulate cortex to behaviour. Brain 118(Pt 1): 279-306.

Ding HK, Teixeira CM, Frankland PW. 2008. Inactivation of the anterior cingulate cortex blocks expression of remote, but not recent, conditioned taste aversion memory. Learn Mem 15: 290-293.

Frankland PW, Bontempi B. 2005. The organization of recent and remote memories. Nat Rev Neurosci 6: 119-130.

Frankland PW, Ding HK, Takahashi E, Suzuki A, Kida S, Silva AJ. 2006. Stability of recent and remote contextual fear memory. Learn Mem 13: $451-457$

Kennerley SW, Walton ME, Behrens TE, Buckley MJ, Rushworth MF. 2006. Optimal decision making and the anterior cingulate cortex. Nat Neurosci 9: 940-947.

Kubik S, Miyashita T, Guzowski JF. 2007. Using immediate-early genes to map hippocampal subregional functions. Learn Mem 14: 758-770.

Lopez J, Herbeaux K, Cosquer B, Engeln M, Muller C, Lazarus C, Kelche C, Bontempi B, Cassel JC, de Vasconcelos AP. 2012. Context-dependent modulation of hippocampal and cortical recruitment during remote spatial memory retrieval. Hippocampus 22: 827-841.

Martin SJ, de Hoz L, Morris RG. 2005. Retrograde amnesia: neither partial nor complete hippocampal lesions in rats result in preferential sparing of remote spatial memory, even after reminding. Neuropsychologia 43: $609-624$.

Morris R. 1984. Developments of a water-maze procedure for studying spatial learning in the rat. J Neurosci Methods 11: 47-60. 
Mouton PR. 2002. Principles and practices of unbiased stereology: an introduction for bioscientists. The Johns Hopkins University Press, Baltimore.

Restivo L, Vetere G, Bontempi B, Ammassari-Teule M. 2009. The formation of recent and remote memory is associated with time-dependent formation of dendritic spines in the hippocampus and anterior cingulate cortex. I Neurosci 29: 8206-8214.

Rudy JW, Biedenkapp JC, O'Reilly RC. 2005. Prefrontal cortex and the organization of recent and remote memories: an alternative view. Learn Mem 12: 445-446.

Squire LR, Alvarez P. 1995. Retrograde amnesia and memory consolidation: a neurobiological perspective. Curr Opin Neurobiol 5: 169-177.

Sterio DC. 1984. The unbiased estimation of number and sizes of arbitrary particles using the disector. J Microsc 134: 127-136.

Sutherland RJ, Hamilton DA. 2004. Rodent spatial navigation: at the crossroads of cognition and movement. Neurosci Biobehav Rev 28: 687-697.

Sutherland RJ, Weisend MP, Mumby D, Astur RS, Hanlon FM, Koerner A, Thomas MJ, Wu Y, Moses SN, Cole C, et al. 2001. Retrograde amnesia after hippocampal damage: recent vs. remote memories in two tasks. Hippocampus 11: 27-42.

Teixeira CM, Pomedli SR, Maei HR, Kee N, Frankland PW. 2006. Involvement of the anterior cingulate cortex in the expression of remote spatial memory. J Neurosci 26: 7555-7564.

Tischmeyer W, Grimm R. 1999. Activation of immediate early genes and memory formation. Cell Mol Life Sci 55: 564-574.
Vetere G, Restivo L, Cole CJ, Ross PJ, Ammassari-Teule M, Josselyn SA, Frankland PW. 2011. Spine growth in the anterior cingulate cortex is necessary for the consolidation of contextual fear memory. Proc Natl Acad Sci 108: 8456-8460.

Wartman BC, Holahan MR. 2013. The use of sequential hippocampal-dependent and -non-dependent tasks to study the activation profile of the anterior cingulate cortex during recent and remote memory tests. Neurobiol Learn Mem 106: 334-342.

Wartman BC, Holahan MR. 2014. The impact of multiple memory formation on dendritic complexity in the hippocampus and anterior cingulate cortex assessed at recent and remote time points. Front Behav Neurosci 8: 128.

Weible AP. 2013. Remembering to attend: the anterior cingulate cortex and remote memory. Behav Brain Res 245: 63-75.

Weissman DH. 2004. Dorsal anterior cingulate cortex resolves conflict from distracting stimuli by boosting attention toward relevant events. Cereb Cortex 15: 229-237.

Zangenehpour S, Chaudhuri A. 2002. Differential induction and decay curves of c-fos and zif268 revealed through dual activity maps. Brain Res Mol Brain Res 109: 221-225.

Received March 21, 2016; accepted in revised form June 7, 2016. 


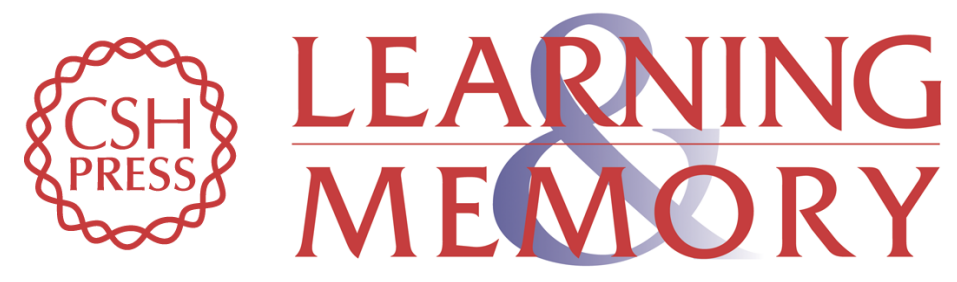

\section{Increased task demand during spatial memory testing recruits the anterior cingulate cortex}

Joshua K. Carr, Neil M. Fournier and Hugo Lehmann

Learn. Mem. 2016, 23:

Access the most recent version at doi:10.1101/Im.042366.116

\section{Supplemental http://learnmem.cshlp.org/content/suppl/2016/08/10/23.9.450.DC1 Material}

References This article cites 26 articles, 8 of which can be accessed free at: http://learnmem.cshlp.org/content/23/9/450.full.html\#ref-list-1

Creative This article is distributed exclusively by Cold Spring Harbor Laboratory Press for the Commons first 12 months after the full-issue publication date (see

License http://learnmem.cshlp.org/site/misc/terms.xhtml). After 12 months, it is available under a Creative Commons License (Attribution-NonCommercial 4.0 International), as described at http://creativecommons.org/licenses/by-nc/4.0/.

Email Alerting Receive free email alerts when new articles cite this article - sign up in the box at the Service top right corner of the article or click here. 